\title{
The Effects of n-3 Fatty Acids and Bexarotene on Breast Cancer Cell Progression
}

\author{
Jessica Trappmann, Susan N. Hawk
}

Department of Nutrition, Exercise and Health Sciences, Central Washington University, Ellensburg, USA.

E-mail: woodys@cwu.edu

Received September $28^{\text {th }}, 2011$; revised October $25^{\text {th }}, 2011$; accepted November $7^{\text {th }}, 2011$.

\begin{abstract}
Breast cancer cell growth can be inhibited in vivo by retinoid X receptor $(R X R)$ specific retinoids. In both animal and cell culture studies, omega-3 fatty acids share growth regulatory effects similar to those of RXR specific retinoids (rexinoids). One synthetic rexinoid, bexarotene (LCD 1069, Targretin), is used clinically to treat cancer patients. Of concern is that some patients are unable to tolerate high doses of such treatment drugs. We hypothesized that $n-3$ fatty acids and bexarotene may work synergistically to slow breast cancer cell growth. To test our hypothesis, we used MCF-7 human mammary carcinoma cells and an in vitro cell culture model. We investigated the relationship between the omega-3 fatty acids docosahexaenoic acid (DHA) and eicosapentaenoic acid (EPA) alone and in conjunction with bexarotene in slowing MCF-7 cell growth. Following a $72 \mathrm{hr}$ incubation with the respective treatments, bexarotene enhanced cell growth $(p<0.05)$ while DHA showed a strong growth inhibitory effect which was not enhanced by the addition of bexarotene $(p<0.05)$. EPA alone was not effective in altering cell growth $(p<0.05)$. Interestingly, when combined with bexarotene, EPA was more effective at slowing cell growth than when cells received EPA alone. Thus, select omega-3 fatty acids alone are more effective than bexarotene in slowing MCF-7 cell progression. However, the use of the RXR-selective retinoids may enhance the growth regulatory mechanisms of the fatty acid EPA.
\end{abstract}

Keywords: Bexarotene, Breast Cancer, Docosahexaenoic Acid, Omega-3 Fatty Acid, MCF-7

\section{Introduction}

Breast cancer is the leading cause of cancer death in women between the ages of 20 and 59 [1]. The high prevalence of breast cancer in the western world suggests a strong association with environmental factors including diet. Specifically, breast cancer risk is linked to high total dietary fat intake, particularly saturated fat [2]. In fact, there is a positive correlation between monounsaturated fats (MUFAs) and increased breast cancer risk [3]. High consumption of omega-6 (n-6) polyunsaturated fatty acids (PUFAs), such as those found in vegetable oils, are also positively correlated with breast cancer risk [3-5]. Conversely, omega 3 (n-3) PUFAs and retinoids exert protective effects and are negatively correlated with breast cancer [5-8]. Of interest is the similar effect of retinoids and n-3 fatty acids in slowing cancer progression in mammary cells. Investigation of such chemotherapeutic and chemopreventative nutrients may produce alternative or supplemental options to current chemotherapeutic treatments. Thus, combining nutrients with prescriptive therapies may allow women to better tolerate their treatments by consuming lower doses of drugs that typically cause adverse side effects.

Epidemiological data supports the notion that a diet high in fish oil may reduce the risk of breast cancer [9]. Long chain n-3 fatty acids such as docosahexaenoic acid (DHA), found abundantly in fatty fish, have been shown to induce apoptosis in the human mammary carcinoma MCF-7 cell line in both in vitro and in vivo rat models [10]. In particular, DHA may increase reactive oxygen species (ROS) and induce death in cancer cells [10]. Of importance to note is that therapeutic levels of DHA (1.8 g) administered in phase II clinical trials improved both time to progression and overall survival in breast cancer patients undergoing chemotherapy without producing adverse toxicity effects [11].

A much larger body of research indicates that retinoids are effective at slowing the development of breast cancer. In vitro studies reveal an inverse relationship between retinoid status or concentration and cancer cell growth [12-14]. In fact, retinoids are effective in treating certain types of cancer in vivo $[7,8]$. In clinical trials, premenopausal women with breast cancer respond positively to 
retinoid treatment $[8,15]$. An even greater reduction of cancer cell growth is observed when retinoids such as all-trans retinoic acid (tRA) are combined with n-3 fatty acids [16]. Thus, a synergistic effect may be occurring between the retinoids and n-3 fatty acid in delaying cancer progression. One mechanism underlying the growth inhibitory action of retinoids on cancer cells includes reduced progression and proliferation by an increase in cellular differentiation and apoptosis [8,12,14,17-20]. DHA is a ligand for peroxisome proliferator-activated receptor $\gamma(\operatorname{PPAR} \gamma)$ [21]. This receptor is part of the nuclear hormone receptor family that heterodimerizes with retinoid X receptors (RXR) [22]. Certain retinoids, such as the RXR-selective retinoid bexarotene (LGD1069, Targretin), are ligands for this receptor [23]. It has also been shown that ligands of RXR and PPAR $\gamma$ trigger an apoptotic response in MCF-7 cells [24].

Though bexarotene's growth-inhibitory effects are not strongly established in the MCF-7 cell line [25], it is possible that retinoid attenuation of n-3 fatty acid effects may be seen when DHA or other n- 3 fatty acids and bexarotene are administered to MCF-7s in combination. Our study will further investigate the relationship between $\mathrm{n}-3 \mathrm{~s}$ and the RXR agonist, bexarotene on the effect of growth in a cell culture model using MCF-7 cells. Results of this experiment could have dietary implications for chemotherapy with complimentary retinoid treatment for cancer patients.

\section{Materials and Methods}

\subsection{Cells and Cell Culture}

MCF-7 human mammary carcinoma cells were obtained from American Type Culture Collection (Manassas, Virginia). Cells were cultured in $20 \mathrm{~mL}$ of Dulbecco's Modified Eagle Media containing 10\% fetal bovine serum (FBS) and $1 \%$ antibiotic (50\% penicillin and 50\% streptomycin), and maintained at $37^{\circ} \mathrm{C}$ with $5 \% \mathrm{CO}_{2}$. All growth media materials were purchased from Fisher Scientific (Pittsburg, Pennsylvania). MCF-7's were cultured in T75 flasks and were between passage 5 and 15 .

\subsection{Retinoid}

Bexarotene was obtained from Santa Cruz Biotechnologies (Santa Cruz, California) and handled under indirect light to prevent photooxidation. Stock solutions were prepared in $100 \%$ ethanol and diluted in growth media. The final concentration of bexarotene added to the culture media was $2 \mu \mathrm{M}$, the approximate $\mathrm{IC}_{50}$ [26].

\subsection{Fatty Acids}

Docosahexaenoic acid (DHA) and eicosapentaenoic acid (EPA) were obtained from Sigma-Aldrich (St. Louis Missouri). Stock solutions of fatty acids were prepared in
$100 \%$ ethanol. Immediately prior to experiments, final stock solutions were prepared using a serial dilution first in ethanol, then culture medium. Both DHA and EPA were added to culture media at final concentrations $\left(\mathrm{IC}_{50}\right)$ of $20.2 \mu \mathrm{M}$ and $54.7 \mu \mathrm{M}$, respectively [10].

\subsection{Cell Counting}

Once confluent, cells were trypsinized and centrifuged at 1800 RPM for 5 minutes. The supernatant was discarded and the cells were resuspended by light vortexing in 1 $\mathrm{mL}$ fresh media. Cells were counted using the trypan blue exclusion method on a Brightline hemacytometer to determine the number of viable cells present in $1 \mathrm{~mL}$.

\subsection{Cell Treatments}

Cells were seeded in 96-well plates at a concentration of 5000 cells per well for proliferation assays. Cells were incubated for 24 hours at $37^{\circ} \mathrm{C}$ with $5 \% \mathrm{CO}_{2}$ in regular culture media containing 10\% FBS to allow time for the cells to adhere to the plate. Media was then removed and replaced with fresh FBS-free media containing one of the following treatments for an incubation period of 72 hours (Table 1).

\subsection{Cell Proliferation Assay}

Cell proliferation was measured by fluorescence using Cell Counting Kit-8 (CCK-8) from Dojindo (Rockville, Maryland) according to the manufacturer's protocol. After 72 hours of incubation with treatment solutions, 10 $\mu 1$ of CCK-8 reagent was added to each well. Plates were incubated for 2 hours, allowing time for production of a water-soluble formazan dye in the presence of viable cells.

\subsection{Cell Proliferation Quantification}

Production of formazan was measured using a Bio-Rad 550 Microplate Reader at an emission of $490 \mathrm{~nm}$. Emission values were compared for treated and non-treated cells to determine differences in viable cell concentration as a marker of cell proliferation.

Table 1. Concentrations of cell treatment solutions.

\begin{tabular}{cc}
\hline Treatment Group & Treatment Concentration \\
Vehicle Control & $0.1 \%$ ethanol \\
DHA & $2 \mu \mathrm{M}$ \\
EPA & $20.2 \mu \mathrm{M}$ \\
Bexarotene + DHA & $54.7 \mu \mathrm{M}$ \\
Bexarotene + EPA & $2 \mu \mathrm{M}+20.2 \mu \mathrm{M}$ \\
\hline
\end{tabular}




\subsection{Statistical Analysis}

Collected data was organized using Microsoft Excel and MiniTab was used to conduct an unbalanced ANOVA test using a general linear regression to determine any significant differences in growth rates among treatment groups at $p<0.05$.

\section{Results}

Treatment of MCF-7 cells with DHA alone and in combination with bexarotene, and EPA in combination with bexarotene resulted in a significant decrease in proliferation following 72 hours of treatment. DHA reduced cell growth by $72 \%$ compared to controls $(p<0.05)$. Overall, DHA alone reduced the growth of MCF-7 cells more than all other treatments except DHA + bexarotene, which was not significantly different from DHA $(p<0.05$, Figure 1). Bexarotene alone resulted in an increased growth rate in comparison to all other treatments and a $14 \%$ increase compared to the control $(p<0.05$, Figures 1 and 2). Though the EPA growth rate did not differ from the control, combined treatment of bexarotene and EPA significantly slowed the growth by $16.1 \%$ when compared to either the control or EPA alone $(p<0.05$, Figure 2).

\section{Discussion}

Though bexarotene is an effective growth inhibitor of estrogen receptor positive $(\mathrm{ER}+) \mathrm{T} 47 \mathrm{D}$ cell types, this effect has not been established in ER+ human mammary carcinoma cells [25]. In the present study, bexarotene enhanced the growth rate of MCF-7 cells. This appears to be a novel effect that has not been demonstrated by other studies.

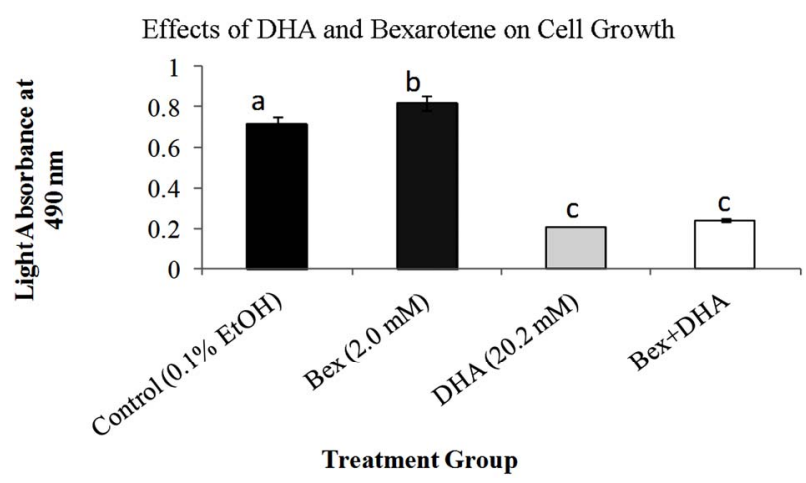

Figure 1. Effects of DHA and bexarotene alone and in combination on MCF-7 cell growth. Bars represent standard error of mean absorbance values for 5 trials. Cell viability was assessed using the CCK-8 assay following 72 hours of exposure to treatments. Cells not exposed to fatty acids or bexarotene were treated with a vehicle control. Bars which do not share letters are statistically different $(p<0.05)$ compared to each other using a general linear regression. Higher absorbance values indicate greater cell viability.

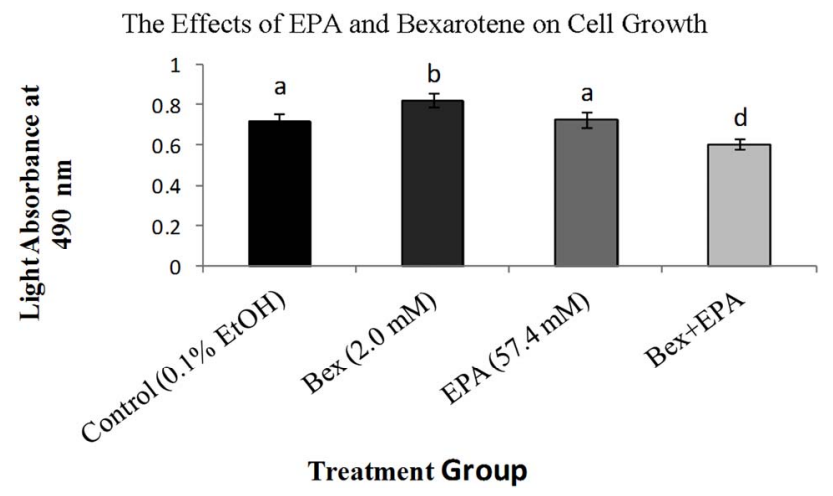

Figure 2. Effects of EPA and bexarotene alone and in combination on MCF-7 cell growth. Bars represent standard error of mean absorbance values for 5 trials. Bars which do not share letters are statistically different $(p<0.05)$ compared to one another. Higher absorbance values indicate greater cell viability.

Consistent with the literature [10], DHA reduced growth of MCF-7 cells in the present study. Previous studies demonstrate that tRA, which targets retinoic acid receptors (RARs), may amplify the effect of the $\alpha$-linolenic acid ( $\alpha$-LA) and DHA in MCF-7 cells [16]. However, at therapeutic doses these naturally occurring retinoids can result in patient toxicity. More selective synthetic retinoids have been examined for their efficacy and toxicity at lower doses and it has been shown that RXR-selective retinoids (rexinoids) have lower toxicity effects than RAR-selective retinoids (reviewed in [25]). In addition, the apoptosis induced by the PPAR $\gamma$ ligand $\gamma$-LA is potentiated by the synthetic RXR-specific ligand AGN194204 [22]. Thus, since bexarotene and DHA may induce cytotoxic effects via similar mechanisms, we postulated that in combined treatments, bexarotene may potentiate the apoptotic effects of DHA.

Despite these findings, the combination of bexarotene and DHA in the present study did not reduce growth of $\mathrm{MCF}-7 \mathrm{~s}$ more than DHA alone. RARs responsive to tRA are found abundantly in ER+ cells such as MCF-7s [22]. However, Crowe et al. demonstrated that MCF-7 cells have a low expression of RXR [22]. Thus, it is possible that bexarotene's lack of DHA-potentiating effect in MCF-7s may be related to a relative lack of abundance of the RXR targeted by bexarotene.

Contrarily, a combination of bexarotene and EPA appear to synergistically reduce the growth of $\mathrm{MCF}-7 \mathrm{~s}$ despite a lack of inhibitory effect seen when these compounds are administered alone. Bexarotene + EPA's effectiveness might be modulated by an entirely different post translational mechanism via protein kinase inhibition. Protein kinases are important regulators of normal cell division and apoptosis and their deregulation is a characteristic of cancer (reviewed in [27]). EPA has been 
shown to be an effective inhibitor of some protein kinases involved in this process and is also effective in restoring sensitivity to tamoxifen in tamoxifen-resistant ER + breast cancer cells [28]. This suggests further research should be done to assess whether bexarotene is also implicated in protein kinase regulation as a possible explanation for the synergistic effects seen in the present study.

In summary, bexarotene is not effective at reducing cell growth in MCF-7s, and stimulates growth. Among the experimental treatments, DHA is most effective at slowing cell growth in MCF-7 cells. Combined treatment with bexarotene and DHA do not slow growth more than DHA alone. Though EPA alone does not significantly alter cell growth in $\mathrm{MCF}-7 \mathrm{~s}$, combined treatment with bexarotene and EPA is effective at impeding cell growth.

Therefore, we conclude that EPA may be effective when combined with drug treatments to slow cancer progression. However, bexarotene alone appears to be a poor treatment drug for MCF-7 cell lines. Further experiments should be conducted on other breast cancer cell lines such as T47D and MDA-MD-468 to explore possible synergistic relationships between bexarotene and long chain n-3 PUFAs.

\section{Acknowledgements}

This research study was sponsored in part by a Science Honors Research Grant from Central Washington University, Ellensburg, WA.

\section{REFERENCES}

[1] A. Jemal, R. Siegel, E. Ward, Y. Hao, J. Xu, T. Murray and M. J. Thun, "Cancer Statistics," CA Cancer Journal for Clinicians, Vol. 58, No. 2, 2008, pp. 71-96. doi; 10.3322/CA.2007.0010

[2] N. F. Boyd, J. Stone, K. N. Vogt, B. S. Connelly, L. J. Martin and S. Minkin, "Dietary Fat and Breast Cancer Risk Revisited: A Meta-Analysis of the Published Literature," British Journal of Cancer, Vol. 89, No. 9, 2003, pp. 1672-1685. doi;10.1038/sj.bjc.6601314

[3] H. Rissanen, P. Knekt, R. Järvinen, I. Salminen and T. Hakulinen, "Serum Fatty Acids and Breast Cancer Incidence," Nutrition and Cancer, Vol. 45, No. 2, 2003, pp. 168-175. doi; 10.1207/S15327914NC4502 05

[4] E. Wirfält, I. Mattisson, B. Gullberg, U. Johansson, H. Olsson and G. Berglund, "Postmenopausal Breast Cancer is Associated with High Intakes of $\omega 6$ Fatty Acids (Sweden)," Cancer Causes and Control, Vol. 13, No. 10, 2002, pp. 883-893. doi;10.1023/A:1021922917489

[5] D. Bagga, K. H. Anders, H.-J. Wang and J. A. Glaspy, "Long-Chain n-3-to-n-6 Polyunsaturated Fatty Acid Ratios in Breast Adipose Tissue from Women with and without Breast Cancer," Nutrition and Cancer, Vol. 42, No. 2, 2002, pp. 180-185.

\section{doi; $10.1207 /$ S15327914NC422 5}

[6] I. M. Berquin, I. J. Edwards and Y. Q. Chen, "MultiTargeted Therapy of Cancer by Omega-3 Fatty Acids," Cancer Letters, Vol. 269, No. 2, 2008, pp. 363-377. doi;10.1016/j.canlet.2008.03.044

[7] C. M. Klass and D. M. Shin, "Current Status and Future Perspectives of Chemoprevention in Head and Neck Cancer," Current Cancer Drug Targets, Vol. 7, No. 7, 2007, pp. 623-632. doi;10.2174/156800907782418347

[8] M. Okuno, S. Kojima, R. Matsushima-Nishiwaki, H. Tsurumi, Y. Muto, S. L. Friedman and H. Moriwaki, "Retinoids in Cancer Chemoprevention," Current Cancer Drug Targets, Vol. 4, No. 3, 2004, pp. 285-298. doi; $10.2174 / 1568009043333023$

[9] J. Kim, S.-Y. Lim, A. Shin, M.-K. Sung, J. Ro, H.-S. Kang, K. Lee, S.-W. Kim and E.-S. Lee, "Fatty Fish and Fish Omega-3 Fatty Acid Intakes Decrease the Breast Cancer Risk: A Case-Control Study," BMC Cancer, Vol. 9, 2009, p. 216. doi;10.1186/1471-2407-9-216

[10] K. S. Kang, P. Wang, N. Yamabe, M. Fukui, T. Jay and B. T. Zhu, "Docosahexaenoic Acid Induces Apoptosis in MCF-7 Cells in Vitro and in Vivo Via Reactive Oxygen Species Formation and Caspase 8 Activation," PLoS One, Vol. 5, No. 4, 2010, p. e10296.

[11] P. Bougnoux, N. Hajjaji, M. N. Ferrasson, B. Giraudeau, C. Couet and O. Le Floch, "Improving Outcome of Chemotherapy of Metastatic Breast Cancer by Docosahexaenoic Acid: A Phase II trial," British Journal of Cancer, Vol. 101, No. 12, 2009, pp. 1978-1985.

[12] L. J. Hayden, S. N. Hawk, T. R. Sih and M. A. Satre, "Metabolic Conversion of Retinol to Retinoic Acid Mediates the Biological Responsiveness of Human Mammary Epithelial Cells to Retinol," Journal of Cellular Physiology, Vol. 186, No. 3, 2001, pp. 437-447. doi; 10.1002/1097-4652(2000)9999:999<000::AID-JCP10 $\underline{43>3.0 . \mathrm{CO} ; 2-5}$

[13] T. K. Hong and Y. C. Lee-Kim, "Effects of Retinoic Acid Isomers on Apoptosis and Enzymatic Antioxidant System in Human Breast Cancer Cells," Nutrition Research Practice, Vol. 3, No. 2, 2009, pp. 77-83. doi; 10.4162/nrp.2009.3.2.77

[14] S. Toma, L. Isnardi, P. Raffo, G. Dastoli, E. DeFrancisci, L. Riccardi, R. Palumbo and W. Bollag, "Effects of AllTrans-Retinoic Acid and 13-Cis-Retinoic Acid on Breast Cancer Cell Lines: Growth Inhibition and Apoptosis Induction," International Journal of Cancer, Vol. 70, No. 5, 1997, pp. 619-627. doi;10.1002/(SICI)1097-0215(19970304)70:5<619::AID$\underline{\text { IJC21>3.0.CO;2-6 }}$

[15] T. Camerini, L. Mariani, G. De Palo, E. Marubini, M. G. Di Mauro, A. Decensi, A. Costa and U. Veronesi, "Safety of the Synthetic Retinoid Fenretinide: Long-Term Results from a Controlled Clinical Trial for the Prevention of Contralateral Breast Cancer," Journal of Clinical Oncology, Vol. 19, No. 6, 2001, pp. 1664-1670.

[16] D. A. Brown, "The Effect of All-Trans Retinoic Acid and Fatty Acids on MCF-7 Breast Cancer Cell Progression," 
MS Thesis, California Polytechnic State University, San Luis Obispo, 2009.

[17] A. Dutta, T. Sen, A. Banerji, S. Das and A. Chatterjee, "Studies on Multifunctional Effect of All-Trans Retinoic Acid (ATRA) on Matrix Metalloproteinase-2 (MMP-2) and Its Regulatory Molecules in Human Breast Cancer Cells (MCF-7)," Journal of Oncology, Vol. 2009, 2009. http://www.hindawi.com/journals/jo/2009/627840/

[18] G. J. Keiloff, C. W. Boone, J. A. Crowell, V. E. Steele, R. A. Lubet, L. A. Doody, W. F. Malone, E. T. Hawk and C. C. Sigman, "New Agents for Cancer Chemoprevention," Journal of Cellular Biochemistry Supplement, Vol. 26, 1996, pp. 1-28.

[19] F. Klamt, F. Dal-Pizzol, D. P. Gelain, R. S. Dalmolin, R. B. de Oliveira, M. Bastiani, F. Horn and J. C. F. Moreira, "Vitamin A Treatment Induces Apoptosis through an Oxidant-Dependent Activation of the Mitochondrial Pathway," Cell Biology International, Vol. 32, No.1, 2008, pp. 100-106. doi;10.1016/j.cellbi.2007.08.018

[20] R. Merino and J. M. Hurlè, "The Molecular Basis of Retinoid Action in Tumors," Trends in Molecular Medicine, Vol. 9, No. 12, 2003, pp. 509-511. doi;10.1016/j.molmed.2003.10.003

[21] S. R. Thoennes, P. L. Tate, T. M. Price and M. W. Kilgore, "Differential Transcriptional Activation of Peroxisome Proliferator-Activated Receptor Gamma by Omega-3 and Omega-6 Fatty Acids in MCF-7 Cells," Mo- lecular and Cellular Endocrinology, Vol. 160, No. 1-2, 2000, pp. 67-73. doi;10.1016/S0303-7207(99)00254-3

[22] D. L. Crowe and R. A. Chandraratna, "A Retinoid X Receptor (RXR)-Selective Retinoid Reveals That RXR-Alpha Is Potentially a Therapeutic Target in Breast Cancer Cell Lines, and That It Potentiates Antiproliferative and Apoptotic Responses to Peroxisome Proliferator-Acti- vated Receptor Ligands," Breast Cancer Research, Vol. 6, No. 5, 2004, pp. R546-R555. doi;10.1186/bcr913

[23] A. Chawla, J. J. Repa, R. M. Evans and D. J. Mangelsdorf, "Nuclear Receptors and Lipid Physiology: Opening the X-Files," Science, Vol. 294, No. 5548, 2001, pp. 18661870. doi; $10.1126 /$ science.294.5548.1866

[24] D. Bonofiglio, E. Cione, H. Qi, A. Pingitore, M. Perri, S. Catalano, D. Vizza, M. L. Panno, G. Genchi, S. A. Fuqua and S. Ando, "Combined Low Doses of PPARgamma and RXR Ligands Trigger an Intrinsic Apoptotic Pathway in Human Breast Cancer Cells," American Journal of Pathology, Vol. 175, No. 3, 2009, pp. 1270-1280. doi;10.2353/ajpath.2009.081078

[25] H.-S. Seo and J. S. Koo, "The Effect of Rexinoid (LGD 1069 and LG100268) on the Growth of Breast Cells," Fifth AACR International Conference on Frontiers in Cancer Prevention Research, Boston, 12-15 November 2006, p. A86.

[26] W. C. Yen, R. Y. Prudente and W. W. Lamph, "Synergistic Effect of a Retinoid X Receptor-Selective Ligand Bexarotene (LGD1069, Targretin) and Paclitaxel (Taxol) in Mammary Carcinoma," Breast Cancer Research and Treatment, Vol. 88, No. 2, 2004, pp. 141-148. doi;10.1007/s10549-004-1426-5

[27] K. Novak, "Protein Kinase Inhibitors in Cancer Treatment: Mixing and Matching?" Keystone Symposium on Protein Kinases and Cancer, Vol. 6, No. 2, Lake Tahoe, California, February 2004

[28] L. A. de Graffenried, W. E. Friedrichs, L. Fulcher, G. Fernandes, J. M. Silva, J.-M. Peralba and M. Hidalgo, "Eicosapentaenoic Acid Restores Tamoxifen Sensitivity in Breast Cancer Cells with High Akt Activity," Annals of Oncology, Vol. 14, No. 7, 2003, pp. 1051-1056. doi;10.1093/annonc/mdg291 